\title{
The differential effect of perspective-taking ability on profiles of cooperative behaviours and learning outcomes
}

\author{
Jolien M. Mouw ${ }^{1}$, Nadira Saab ${ }^{2}$, Hannie Gijlers ${ }^{3}$, Marian Hickendorff ${ }^{4}$, \\ Yolinde van Paridon ${ }^{4} \&$ Paul van den Broek ${ }^{4}$ \\ ${ }^{1}$ Department of Educational Sciences, University of Groningen, the Netherlands \\ ${ }^{2}$ ICLON, Graduate School of Teaching, Leiden University, the Netherlands \\ ${ }^{3}$ Department of Instructional Technology, University of Twente, the Netherlands \\ ${ }^{4}$ Institute of Education and Child studies, Leiden University, the Netherlands
}

\begin{abstract}
The present study aims to provide a systematic understanding of how perspectivetaking ability contributes to primary-school students' cooperative behaviours and learning outcomes. The present study is frontline as we combined personoriented (e.g., describing patterns of behaviours based on individual characteristics), process-oriented (e.g., examining factors affecting the quality of cooperative behaviours), and effect-oriented (e.g., examining the effect of cooperative learning on individual learning outcomes) analytical approaches within one research framework. In addition, we adhered to the multi-dimensional nature of perspective-taking ability and differentiated between social and cognitive perspective-taking ability while taking into account the contribution of perspective-taking ability at both the individual level and group level (i.e., heterogeneous and homogeneous perspective-taking ability groups) to cooperative behaviour profiles and learning outcomes of primary-school children. Based on transcribed episodes of interaction of 115 fifth-grade students, four different profiles of cooperative behaviours were discerned: captains, hard workers, switchers, and passive participants. We found that these profiles are related to perspective taking conceptualized at the group level, but not to individual-level perspective-taking ability. Profile membership, cognitive perspective-taking ability, and group-level perspective-taking ability could not predict students' learning outcomes. Social perspective-taking ability and reading comprehension did positively predict learning outcomes. Our findings add to existing knowledge as they suggest that the influence of perspective-taking ability on cooperative behaviours and learning outcomes is susceptible to the conceptualization (i.e., cognitive vs. social) and measurement level (i.e., individual vs. group level) of perspective-taking ability.
\end{abstract}

Keywords: Cooperative learning; perspective-taking ability; group composition; profiles of cooperative behaviours; learning outcomes.

Corresponding author: Jolien M. Mouw (j.m.mouw@rug.nl); Department of Educational Sciences, University of Groningen, Grote Rozenstraat 3, 9712 TG Groningen, the Netherlands. DOI:

https://doi.org/10.14786/flr.v8i6.633 


\section{Introduction}

Many primary school teachers implement cooperative learning activities on a daily base because this educational method can enhance students' academic performances, motivation, and social skills (e.g., Gillies, 2014; Johnson \& Johnson, 2009). The ultimate goal of a cooperative learning activity is to engage students in promotive interaction in which learning can become meaningful. During promotive interaction, group members ideally participate actively, share information, help each other, and reach a common ground. These cooperative processes are often equated with effective cooperative behaviours as they support a group to attain its goals and enable individual and group learning processes to occur. However, not everyone finds it easy to cooperate or knows how to cooperate effectively as the coordination of activities, motivations, and goals is often a difficult task, especially when group members hold diverging opinions or reason from different points of view (Webb, 2013). A potential black-box mechanism underlying promotive interaction in which group members engage in effective cooperative behaviours could be perspective taking (Johnson, 1975a, 1975b; Tjosvold, Johnson, \& Johnson, 1984). For example, in research on adults, it is assumed that perspective taking supports the formation of social bonds and facilitates cognitive and communicative processes and behaviours such as problem solving and conflict resolution underlying promotive interaction (Galinsky, $\mathrm{Ku}, \&$ Wang, 2005; Johnson, 1975a, 1975b).

Although some research has been conducted on adults' perspective-taking abilities in the context of cooperative learning, a systematic understanding of how perspective-taking ability contributes to several aspects of primary-school students' cooperative learning processes is lacking. For example, most studies focus on the relation between perspective taking and broad categories of communicative processes relevant for cooperation such as prosocial behaviours, conflict resolution, and problem solving (e.g., Cigala, Mori, \& Fangareggi, 2015; Falk \& Johnson, 1977; Tjosvold et al., 1984; Trötschel, Hüffmeier, Loschelder, Schwartz, \& Gollwitzer, 2011). However, no single study has evaluated the relation between perspective-taking ability and specific effective cooperative behaviours such as basic communicative functioning, helping behaviour, and grounding processes. More specifically, it is not clear if (and how) individual differences in perspective-taking ability yield differences in the whole range of cooperative behaviours in which primary-school students engage during face-to-face group work activities, and how this relates to subsequent learning outcomes. In addition, cooperative learning involves individual students working together in groups, and both individual and group-level characteristics (i.e., how students are grouped) shape interaction during group work and affect the quality of learning (e.g., Arjava, Salovaara, Häkkinen, \& Järvelä, 2007; Janssen, Cress, Erkens, \& Kirschner, 2013). However, the effects of individual-level and group-level perspective-taking ability on cooperative behaviours and learning outcomes have not yet been evaluated simultaneously. Therefore, the present study strives to add to existing knowledge by differentiating between types of perspective-taking abilities and taking into account the contribution of both individuallevel and group-level perspective-taking ability (i.e., heterogeneous and homogeneous perspectivetaking ability groups) to cooperative behaviours and learning outcomes of primary-school children.

Below we present our theoretical framework in which we first elaborate on cooperative behaviours that are essential for the establishment of promotive interaction. We then continue by introducing perspective-taking ability and describe how types of individual-level and group-level perspective-taking ability could facilitate promotive interaction during group work and stimulate subsequent learning. We then address some conceptual and methodological challenges that need to be taken into account when evaluating the role of perspective taking during cooperative learning.

\subsection{Establishing promotive interaction}

The basic premise of effective cooperative learning is that learning becomes meaningful during promotive interaction between two or more communicative partners who attempt to learn something together (e.g., Johnson \& Johnson, 2009). In promotive interaction, group members create the ideal 
circumstances for themselves and their peers to learn by participating actively, helping others, supporting each other's thinking processes, sharing information and resources, and negotiating possible solutions. Such a rich learning environment allows for collaborative knowledge construction and can be beneficial for understanding and learning processes (e.g., Johnson \& Johnson, 2009; Webb, 2013), provided that students engage in effective cooperative behaviours known to bring about higher individual learning gains (e.g., Erkens, Jaspers, Prangsma, \& Kanselaar, 2005; Gillies, 2014; Webb, 2013). Below we will discuss various types of effective cooperative behaviours that can be subsumed under three categories: Basic communicative functioning, helping behaviour, and grounding processes.

The first category of effective cooperative behaviours concerns aspects of basic communicative functioning such as giving compliments, appropriate turn-taking, listening actively (for example, acknowledging a message is received by responding with "hmm hmm"), and encouraging group members to continue their reasoning. If groups of students adhere to these basic rules for communication, a positive climate is created in which all group members feel empowered to contribute (Wegerif \& Mercer, 1996).

The second category of effective cooperative processes entails helping behaviours. In specific, it is imperative that students engage in high-quality helping behaviours during peer interaction and ask precise questions and help other group members by giving elaborate and detailed explanations. These processes stimulate cognitive restructuring and enable group members to identify and correct possible flaws or misconceptions in their reasoning (e.g., King, 2002; Webb, 2013). Most studies indeed have found that high-quality helping behaviour can be conducive to individual learning, whereas low-quality helping behaviours such as asking non-specific questions and giving and receiving simple answers are less beneficial (e.g., Webb, Farivar, \& Mastergeorge, 2002; for an exception see Mouw, Saab, Janssen, \& Vedder, 2019).

The third category of effective cooperative processes pertains to grounding behaviours, as all task-related and social activities taking place during group work need to be planned, monitored, and coordinated. Only then are groups able to reach a shared frame of reference and co-construct a common language that enables them to communicate, discuss, and appraise individual perspectives (e.g., Clark \& Brennan, 1991; Di Eugenio, Jordan, Tomason, \& Moore, 2000; Erkens, 2004; Erkens et al., 2005; Janssen, Erkens, Kirschner, \& Kanselaar, 2012). Erkens, Jaspers, Prangsma, and Kanselaar (2005) found that these planning, monitoring, and coordination processes (such as focusing, checking, and argumentation) can be conducive to learning as it helps groups to obtain a common ground and facilitates in-depth processes of collaborative knowledge construction.

\subsection{Perspective taking: A prerequisite for establishing promotive interaction}

We posit that fruitful group work also requires the awareness that others may interpret the world or a task at hand from a different point of view (e.g., Johnson, 1975b). For example, if cooperating group members are unable to recognize their differences in knowledge, motivations, or expectations, they are at risk of miscommunication, impasses, and even conflict (e.g., Pronin, Puccio, \& Ross, 2002; Trötschel et al., 2011); all processes that make it difficult to reach a common ground. Perspective-taking ability enables co-operators to explore differences in each other's points of view and helps to understand that resulting disagreements do not necessarily reflect hostile communication, and thus sets the ground for promotive interaction (Beersma, Bechtoldt, \& Schouten, 2018; Järvelä \& Häkkinen, 2002). In this study, we conceptualize perspective taking as the ability to (mentally) place yourself in someone else's shoes, to assess social situations adequately, to understand, infer, and appropriately respond to expectations, thoughts, feelings and emotions of another person, and the motivation to do so (e.g., Cigala et al., 2015; Davis, 1983).

In the context of cooperative learning, Johnson (1975b) found that 9-to 10-year-old students' affective perspective-taking abilities are correlated with their predisposition to cooperate. In addition, some studies have demonstrated that perspective-taking processes can facilitate more positive and 
effective communication processes. For example, training pre-schoolers' perspective-taking abilities resulted in the tendency to more often behave in a prosocial manner during interactions with their peers

(Cigala et al., 2015). The 3- to 5-year-old children who received this training more often engaged in helping and sharing behaviours as compared to their peers who did not receive training. In adult samples, it is shown that perspective taking can have a positive impact on group processes. For example, adults with high perspective-taking skills are more capable to match the content of their messages to the recipient in such a way that others better understand what is being said (e.g., Johnson, 2015). Moreover, when working in adult pairs, more information is brought into a conversation, understood, and remembered when one of the co-operators takes the perspective of the other as a mechanism to overcome conflict (Johnson, 1971).

In addition, perspective taking enables consensus making, the appropriate use of social and interpersonal skills, supportive and respectful behaviours, trust building, and leadership, and thereby facilitates the establishment of a positive climate in which group members possibly feel safer to contribute (e.g., Järvelä \& Häkkinen, 2002; Trötschel et al., 2011). Last, perspective taking plays a role in the perceived self-other overlap and thus determines the degree to which group members experience similarities and feel connected to each other (e.g., Davis, Conklin, Smith, \& Luce, 1996; Galinsky et al., 2005). This way, perspective taking can strengthen social bonds, facilitates social coordination, promotes group cohesion, and can tie individuals together in a group (Galinsky et al., 2005; Galinsky \& Moskowitz, 2000).

\subsection{Considerations for evaluating the role of perspective taking during cooperative learning}

To summarize, it seems that previous studies (primarily focussing on adult samples) have evidenced a positive correlation between perspective taking and aspects of cooperative learning. However, more recent research advocates the notion that perspective taking should be considered and operationalized as a multi-dimensional construct as it appraises a visual, cognitive, and social (e.g., affective) component (Cigala et al., 2015). Visual perspective taking helps to determine the spatial position of objects and understanding and supports predicting others' visual and physical experiences (Michelon \& Zachs, 2006). Cognitive perspective taking comprises the ability to infer, understand, and reason about another person's motivations, intentions, and thoughts. Social perspective taking strongly relates to empathy and concerns understanding others' emotional states or experiencing these emotions yourself (Cigala et al., 2015). In the context of cooperative learning-which is characterized by the verbal exchange of thoughts, opinions, and ideas within a social-emotional context—cognitive and social perspective-taking processes are of high instrumental purpose.

A few studies that touched upon the assumed relation between perspective taking and cooperative processes did distinguish between these types of perspective taking. However, their conclusions pertain to either cognitive or social perspective taking (e.g., Falk \& Johnson, 1977; Tjosvold \& Johnson, 1977), and we are not aware of any study in which the relative contribution of cognitive and social perspective-taking ability to cooperative learning has been evaluated simultaneously. However, such a unidimensional conceptualization of perspective taking is problematic as this provides no insight into a possible differential effect of either type of perspective-taking ability on cooperative processes, even though it is not unlikely that cognitive and social perspective-taking ability relate to different types of cooperative behaviours. For example, based on the study of Falk and Johnson (1977), one would expect that students with higher cognitive perspective-taking abilities more often engage in task-oriented grounding behaviours such as monitoring, planning, and coordination. Moreover, in line with Cigala, Mori, and Fangareggi (2015), a positive relation between high-quality helping behaviour and social perspective taking is most likely. In addition, the few studies describing the relation between perspective taking and cooperative processes have hardly ever extended their findings by testing a possible direct relation between perspective-taking ability and learning outcomes (e.g., Järvelä \& Häkkinen, 2002; Johnson, 1975b; Tjosvold \& Johnson, 1977; Tjosvold et al., 1984; Trötschel et al., 2011). 
Another methodological consideration concerns the fact that cooperative learning involves individual students working together in groups, and both individual characteristics as well as grouplevel attributes (i.e., how students are grouped) are known to affect the success of a cooperative learning activity (e.g., Arjava et al., 2007; Cohen, 1994; Janssen et al., 2013). Therefore, it is important to determine if (and how) individual perspective-taking ability and perspective-taking ability conceptualized as a group characteristic (i.e., group formation based on individual students' perspective-taking abilities) influence the effectiveness of cooperative learning in terms of cooperative behaviours and learning outcomes. However, until now, the majority of research on the effects of heterogeneity and homogeneity of groups is based on variance in cognitive ability levels (e.g., Baer, 2003; Cohen, 1994), whereas there is a scarcity of research focusing on the heterogeneity of social skills. One of the few exceptions is the work of Falk and Johnson (1977), where perspective-taking ability was taken into account at the group level (i.e., grouping based on perspective-taking ability) and instructional level (conditions varying in perspective-taking instructions). The solutions of groups of student nurses who were instructed to take their group members' perspectives were of a higher quality and contained more creative suggestions as compared to the solutions of students who approached the task more individualistically. Falk and Johnson also found that students in the perspective-taking condition were more cooperative and engaged in fewer conflicts than the students in the egocentric condition, but across these conditions, heterogeneous and homogeneous groups did not differ in the effectiveness of their communication. However, the authors formed heterogeneous and homogeneous groups based on how similar student nurses ranked the relative importance of items for surviving on the moon. It can be argued whether this instrument gauged perspective-taking ability (i.e., the ability to view the world from another person's perspective) or merely mapped students' controversy regarding their views on a certain problem-solving activity. Hence, it is not only unclear if students with higher and those with lower cognitive or social perspective-taking abilities engage in different grounding processes, helping behaviours, and basic communicative skills during group work: the same question arises with regard to groups varying in their group members' perspective-taking abilities (i.e., heterogeneous and homogeneous groups).

Last, many studies on cooperative learning have exclusively adopted an effect-oriented research approach and delineated which distinct cooperative behaviours positively affect learning (see Webb, 2013, for a review; Asterhan \& Schwarz, 2016; Webb et al., 2002). However, this does not fully capture what actually happens during peer interaction. Co-operators do not use a single behaviour in isolation but instead engage in combinations of cooperative behaviours and activities in interaction with their peers. Hence, a more fruitful approach would be to focus on the combinations or patterns of cooperative behaviours students use during a complete episode of group work and capture these patterns in profiles of cooperative behaviours (Driskell, Driskell, Burke, \& Salas, 2017), for example, by using a Latent Profile Analysis. With this technique, it is possible to examine how perspective-taking ability is related to differences in students' engagement in patterns of essential cooperative behaviours throughout a cooperative learning activity (i.e., profiles of cooperative behaviours) and to subsequently evaluate how these profiles of cooperative behaviours relate to learning outcomes.

\subsection{The present study}

Based on our argumentation presented above, we emphasize the importance of understanding how grouping students could influence the quality of interaction and the extent to which learning is promoted. Therefore, our goal is to evaluate the relation between types of individual-level and grouplevel perspective-taking ability (i.e., heterogeneous and homogeneous groups), patterns of cooperative behaviours, and learning outcomes. We will combine person-oriented (e.g., describing the relation between profiles of cooperative behaviours and individual characteristics), process-oriented (e.g., examining factors affecting the quality of cooperative processes), and effect-oriented (e.g., examining the effect of cooperative learning on individual learning outcomes) research approaches within one framework as we aim to answer the following questions: 
1. Are profiles of cooperative behaviours related to individual students' cognitive and social perspective-taking abilities?

2. Do students in heterogeneous and homogeneous perspective-taking groups engage in different profiles of cooperative behaviours?

3. How do individual-and group- level perspective-taking ability and cooperative behaviour profiles contribute to individual students' cooperative learning outcomes?

For the first research question, we follow the work of Järvelä and Häkkinen (2002) and hypothesize that cooperative behaviour profiles of students with higher perspective-taking abilities can be characterized by engagement in more effective cooperative behaviours (i.e., higher occurrence of basic communicative functioning, helping behaviours, and grounding processes) as compared to students with lower perspective-taking abilities. More specifically, based on the study of Falk and Johnson (1977), we expect that students with higher cognitive perspective-taking abilities are more often allocated to profiles with higher frequencies of task-oriented behaviours such as the input of new information, monitoring, and planning activities (i.e., grounding activities). Furthermore, we expect that students with higher social perspective-taking abilities more often engage in cooperative behaviour profiles with a dominance of high-quality helping behaviours (Cigala et al., 2015). Regarding the second research question, we expect that students in heterogeneous and homogeneous perspective-taking groups engage in different cooperative behaviours, with a higher prevalence of effective cooperative behaviour profiles in homogeneous groups (i.e., all group members with strong perspective-taking abilities) as compared to heterogeneous groups. Regarding the third research question, we expect a positive relation between perspective-taking ability and subsequent learning gains, and that this effect will be particularly apparent for cognitive perspective taking (Falk \& Johnson, 1977; Johnson, 1971). Furthermore, we expect a positive relationship between cooperative behaviour profiles with higher frequencies of effective behaviours (i.e., basic communicative functioning, grounding behaviour, and high-quality helping behaviour) and learning outcomes.

\section{Methodology}

\subsection{Participants}

A total of 120 fifth-grade students (55 girls, $M_{\text {age }}=10.58$ years, age range: $9.5-11.92$ years) from five classes from three primary schools in the Netherlands participated in a three-session classroom-based study. We asked parents or caretakers to provide active written consent for their child(ren)'s participation. The ethics committee of the Institute of Education and Child Studies at Leiden University approved the procedures of this study.

\subsection{Perspective taking}

During the first session, we assessed our participants' cognitive and social perspective-taking abilities using (scales from) three different tests. This way, we were able to encapsulate several distinctive aspects of perspective taking in our assessment, as described by Mouw, Saab, Pat-El, and Van den Broek (2019).

\subsubsection{Cognitive perspective taking}

In this study, we define cognitive perspective taking as the ability to mentally infer, understand, and reason about another person's motivations, intentions, and thoughts. It pertains to one's cognitive capacity to process and understand another's point of view (e.g., Cigala et al., 2015). We used two subscales of the Interpersonal Reactivity Index (IRI; Davis, 1983), namely the fantasy and perspective 
taking scales, as measures of cognitive perspective taking. Participants rated 14 items on a 5-point Likert scale $(1=$ does not describe me well and $5=$ describes me very well $)$. An example item is: "I try to understand my friends better by imagining how something looks like from their perspective." The internal consistency of both seven-item scales is sufficient (fantasy: $\alpha=.80$; perspective taking: $\alpha=.72$ ).

Cognitive perspective taking entails a second distinct—yet essential—facet, namely Theory of Mind (Cigala et al., 2015; Wellman, 2018). Therefore, we decided to administer the Read the Mind in the Eyes-Test (RME; Baron-Cohen, Wheelwright, Hill, Raste, \& Plumb, 2001) as a measure of cognitive perspective taking in addition to the two IRI-scales. The child version of the RME measures how well children can attune to the mental state of others (Vogindroukas, Chelas, \& Petridis, 2014). For each of the 28 items, children are asked to attribute the relevant state of mind after having been presented with a photograph of a person's eyes. The RME is a multiple-choice test: Participants have to select one of four given mental states, and a point is given for each correct answer. Internal consistency of this test is sufficient ( $\alpha=.69$; Vogindroukas et al., 2014).

\subsubsection{Social perspective taking}

Feelings of empathy and experiencing and understanding emotional aspects of social situations (such as emotional states) are indicators of social perspective-taking ability. Therefore, we used the empathic concern scale of the IRI (Davis, 1983) to assess the first aspect of social perspective-taking ability. The empathic concern scale measures emotional reactions and other-oriented feelings of empathy and sympathy. Participants rated this scale's seven items on a 5-point Likert scale $(1=$ does not describe me well and 5 = describes me very well). An example item is: "I often have concerned feelings for people less fortunate than me." The Dutch child version of the empathic concern scale was sufficiently reliable $(\alpha=.73)$.

The Revised Emotion Awareness Questionnaire (EAQ-30r; Rieffe, Oosterveld, Miers, Terwocht, \& Ly, 2008) was used as a second measure to assess children's social perspective-taking abilities. This 30-item questionnaire gauges how students recognize, understand, think, and feel about others' and their own emotional states; all of which are aspects of emotional functioning that are essential for emotional processing and reasoning, and thus, for social perspective taking (Ruby \& Decety, 2004). The EAQ-30r measures six aspects of emotional functioning (differentiating emotions, verbal sharing, not hiding, bodily awareness, other's emotions, and analyses of emotions) on a Likert scale that ranges from 1 (not true) to 3 (often true). It should be noted that the verbal sharing scale comprises three items and the differentiating emotions scale comprises seven items, whereas all other scales consist of five items. In the current sample, we found that the internal consistency of the six scales ranges between .64 and .78 .

\subsubsection{Group formation}

Because we were curious to find out if group composition based on perspective-taking ability influenced students' cooperative behaviours and subsequent learning outcomes, we formed groups of three to four students based on their perspective-taking abilities. We formed eight homogeneous and 23 heterogeneous groups. In homogeneous groups, only students with higher perspective-taking abilities (i.e., those who scored above the classroom average on the RME, on a combined IRI scale score, and on at least three out of six EAQ-scales) were placed together. We did not form low-level homogeneous perspective-taking groups as this often concerned students of whom their teachers indicated that being placed together would lead to tension between students and undesired situations (for example, because of previous conflicts or bullying behaviours). Students in heterogeneous groups varied in their perspective-taking abilities (i.e., mixed perspective-taking ability groups in which students with high, low, and average scores were placed together). 


\subsection{Training and cooperative learning task}

At the start of the second session, an instruction video was shown in which ten-year-old peers modelled both desired and undesired cooperative behaviours. The researchers discussed these fragments with the students and, using a structured questioning technique, six main rules for effective cooperative learning were abstracted. These rules pertained to effective grounding techniques, high-quality helping behaviour, and basic cooperative behaviours such as turn-taking (Janssen et al., 2012; Johnson \& Johnson, 2009; Webb et al., 2002). The rules, as outlined in Table A1 (Appendix), were written down on a poster that was displayed in the classroom where students worked on their cooperative assignments.

Immediately after receiving the cooperative-learning training, students practised these rules and desired behaviours in their groups as they worked on a Jigsaw history task facilitating resource interdependence (e.g., Ortiz, Johnson, \& Johnson, 1996). The first part of the task was to collaboratively read a general introduction that set the scene for a historical event (i.e., the opening of the first railway line in the Netherlands). Group members then individually continued with the second part of the task, which was to read a text in which the historical happening was described from one of four protagonistspecific perspectives. Because each group member read about the historical event from a different perspective, they each had different information at their disposal. During the third part of the task, students were challenged to discuss unique pieces of information presented in each of the four texts and had to reach a common ground to be able to write a brochure for a history museum. During the third session, groups of students worked a similar Jigsaw-task (i.e., learning about a historical event from unique perspectives), but now learned about child labour in the 19th century.

The texts (fictional narratives) were written in such a manner that students with a fourth-grade reading comprehension and/or technical reading ability level were able to read them (CLIB; Evers, 2008). The suitability and readability of the texts and the corresponding knowledge test (discussed below) were discussed by a group of cooperative learning researchers and primary-school teachers $(N$ =4) and subsequently evaluated in a pilot study in which 133 fifth-grade students ( 72 girls, $M_{\text {age }}=10.60$ years, age range: 9.83-12.25 years) from seven classes from six Dutch schools participated. Based on this pilot study, minor adjustments - mostly pertaining to vocabulary - were made to the texts and the task description.

\subsection{Learning outcomes}

Students filled out a 10-item test after completing the group assignment. This researcherconstructed test was used to assess individual students' knowledge of the historical event they read about and have discussed during the group assignment. Seven open questions and one multiple-choice question assessed factual knowledge or general information incorporated in all four texts. In addition, students had to answer two integration questions for which they had to combine pieces of unique information presented across the four texts. This means that they could only give a partial solution if they merely recalled information they had read themselves instead of using information from other texts as discussed during group work. A point was given for each correct answer, and a total of 11 points could be awarded as one question comprised an ' $a$ ' and ' $b$ ' part. The first and fifth author (who had no knowledge of the type of group a student was placed in) marked these tests individually and agreed on $94.78 \%$ of all points awarded.

The points awarded to this knowledge test served as a proxy measure for student's understanding of the learning materials, and from here on will be referred to as individual learning outcomes. No measure of group learning outcomes was included in our analyses because the quality of the group product (i.e., the brochure) did not always reflect the quality of the group's cooperative processes. For example, some groups engaged in high-quality interaction in which they discussed a lot of information, evaluated their perspectives thoroughly, and continuously monitored their strategies. These important processes took up much time and effort; time that could no longer be spent on finishing a high-quality final product. 


\subsection{Cooperative behaviours}

Thirty-one groups were videotaped while working on their cooperative task during the third session. However, due to technical difficulties, only 30 episodes of interaction could be transcribed and used for further analyses. Following the works of Erkens et al. (2005), Janssen, Erkens, Kirschner, and Kanselaar (2012), Webb, Farivar, and Mastergeorge (2002), and Wegerif and Mercer (1996), the coding scheme included seven types of effective cooperative behaviours to operationalize the three (previously discussed) categories of cooperative behaviours that are considered to be essential for establishing promotive interaction: Basic communicative functioning (i.e., encouraging each other), grounding activities (i.e., checking, monitoring, planning, and input of new information), and helping behaviours (i.e., asking specific questions and giving explanations). We added task-related activities such as reading out loud as an eight category of effective behaviours and included three ineffective, but frequently occurring, low-quality helping behaviours (i.e., asking non-specific questions, giving answers, and offtopic behaviours) in our coding scheme. This way, it is possible to examine the whole range of behaviours students engage in during peer interaction. Examples of each of the 11 categories of cooperative behaviours are presented in Table 1. Transcripts were coded in the Multiple Episode Protocol Analysis tool (MEPA, version 4.10; Erkens, 2005). In total, 13783 utterances $\left(M_{\text {length transcript }}=\right.$ 459.43 utterances, $S D=137.19$ ) were coded independently by two coders (i.e., the first and fifth author). The interrater reliability, calculated on approximately $15 \%$ of the transcripts, was satisfactory $(\kappa=.82)$.

\subsection{Reading comprehension}

Individual levels of reading comprehension were included in our examination because students worked on a cooperative task highly narrative in nature. The Dutch National Institute for Educational Measurement (CITO) developed a curriculum-independent test that is used nationally to assess primaryschool students' reading comprehension abilities (CITO-Test Reading Comprehension; Egberink, Janssen, \& Vermeulen, 2015). Students' reading comprehension ability ranges from A to E levels (A = $25 \%$ best scoring students; $\mathrm{B}=25 \%$ on or just above average; $\mathrm{C}=25 \%$ below average; and levels $\mathrm{D}$ and $\mathrm{E}$ together comprise the $25 \%$ lowest-scoring students). 
Table 1

Scheme for coding cooperative behaviours

\begin{tabular}{ll}
\hline Code & Description \\
\hline Basic communicative & Statements encouraging other group members (either to elaborate \\
$\begin{array}{l}\text { functioning } \\
\text { and/or continue, or giving each other compliments) }\end{array}$
\end{tabular}

functioning

High-quality helping behaviour

Ask specific questions

\section{Give explanation}

\section{Grounding}

Input new information

Checking

Monitoring

Planning

Task-related

Low-quality helping behaviour

Ask non-specific question An indication that something is not understood, but the question or statement is not specific enough to pinpoint what exactly is not

clear. not understood or clear.

Giving elaborate explanations, reasons, and/or arguments. conversation. Discussing (information from) individual texts with the group. Utterances need to contain a unique new contribution background knowledge.

Verifying if all group members understand the task or an explanation given. Checking if all group members agree on a decision.

Maintaining or renewal of focus. Utterances indicating evaluation of what works and what does not. Reflection on time path. Social monitoring related to cooperative learning rules. Comparison of texts. Comparing current progress to previous tasks.

Discussing and deciding on a strategy or approach. Allocation of tasks. Statements often incite action.

Task-relevant utterances as reading (parts of) the assignment out loud, thinking aloud, and scaffolding (individual) progress.

Repeating previous statements to facilitate the writing process. are part of a groups' strategy.
Example

"Hmm, ok. Continue"

"That was an excellent idea!"

"Could you explain how a steam engine works?" "I don't know how to spell Bastille; can you help me?"

"The factory director was not happy with this law Complementing (previously given) explanations to make it clearer.

because children were much cheaper than adults."

"In the $19^{\text {th }}$ century, many children had to work in factories."

"In my text, it's written that..." not previously discussed relating either to the text or to individuals' Utterances concerning materials needed for group processes or that
"Does everyone understand what we need to do?"

"Do you understand what he said?"

"Does everyone agree?"

"That doesn't seem right! Because if you..."

"Only 5 minutes left, we should hurry!"

"Violet, stop it! We need to do it together."

"The main characters in our texts disagree."

"Why don't we do it like this?"

"First we will write down a general introduction."

"I've already finished."

"In ... 1860... many... children..." (Thinking aloud while writing or citing what another group member needs to write)

"I need your marker."

"Huh?" "What?"

"I don't understand." 
Give answer

Off topic
Only give an answer or confirmation without explaining why.

All utterances indicating off-topic behaviours (jokes, references to irrelevant personal experiences, contributing to or continuing disturbances) or lack of interest.
"Yes, I agree." "Ok."

"Have you seen this video on YouTube?" "Whatever, I don't care." 


\subsection{Procedure}

Students' perspective-taking abilities were measured during a first, 30-minute session. Based on their perspective-taking skills, we placed students in heterogeneous or homogeneous groups. At the start of the second session, students received a 20-minute training on cooperative behaviours and rules for effective group work were abstracted. Immediately after receiving this training, students familiarised themselves with these rules while working on a practice task. This cooperative Jigsaw-task asked students to jointly read a general introduction in which a historical event (i.e., the opening of the first railway line) was introduced. Students then continued reading a text individually. The group members cooperatively wrote an information brochure based on information offered in all texts. During the third session, groups of students worked a similar Jigsaw-task (i.e., learning about a historical event from unique perspectives), but now learned about child labour in the 19th century. All peer interaction taking place during this third session was videotaped. Groups of students on average worked on the cooperative task for 35 minutes. An individual knowledge test was administered directly after group work. All measurements and activities took place in students' own classrooms.

\subsection{Statistical analyses}

Five students were absent during the third meeting. As a result, our analyses are based on the behavioural data and learning outcomes of 115 students. Below, we will first describe how the distinct profiles of cooperative behaviours were discerned. Then, we will set forth which statistical approaches were used to answer our research questions.

\subsubsection{Students' profiles of cooperative behaviours}

With regard to the behavioural data, we posit that group members do not use a single behaviour in isolation. Instead, they engage in combinations of activities in interaction with their peers. Therefore, we followed a person-oriented approach and focused on profiles of cooperative behaviours (i.e., combinations of cooperative behaviours) students used during a whole episode of group work to capture all behaviours occurring during peer interaction. These profiles are used in all subsequent analyses to answer our research questions. To identify distinct profiles of students' cooperative behaviours we conducted a Latent Profile Analysis (LPA). LPA is a statistical technique that belongs to the family of model-based clustering techniques. It aims to trace the heterogeneity in observed responses to a number of distinct classes or clusters, each with its characteristic response profile (e.g., Oberski, 2016). LPA not only captures quantitative individual differences (where individuals are placed on a scale from low to high frequency of behaviours); it can also reveal qualitative individual differences (for a conceptual introduction to the application of this technique in learning research, see Hickendorff, Edelsbrunner, McMullen, Schneider, \& Trezise, 2018). The program Latent Gold 5.1 was used to conduct the LPA on the frequency of the 11 cooperative behaviours described in Section 2.5 (Vermunt \& Magidson, 2013). As a first step, the number of profiles needs to be determined. Models with increasing numbers of profiles were estimated. Based on a combination of statistical fit measures and conceptual appeal the number of profiles was selected, and the profiles were interpreted.

\subsubsection{Profiles of cooperative behaviours in relation to individual-and group-level perspective-taking ability}

To investigate the relation between students' profiles of cooperative behaviours and individuallevel perspective-taking ability, we ran two univariate ANOVAs with students' profile membership (obtained by modal assignment; Collins \& Lanza, 2010) as the independent variable and individuallevel cognitive and social perspective-taking ability as dependent variables. To this end, we calculated a compound cognitive perspective-taking score by averaging students' normalized scores on the RME and the IRI fantasy and IRI perspective-taking scales. Likewise, we constructed a social perspectivetaking scale score by normalizing and averaging students' ratings on the six EAQ scales and the IRI 
empathy scale. The descriptive statistics of all variables (prior to normalization and scale construction) are presented in Table 2 .

A Chi-square test was then used to evaluate the relation between cooperative behaviours and perspective taking at the group level (i.e., heterogeneous and homogeneous group composition based on group members' perspective-taking abilities). More specifically, we investigated if the prevalence of the discerned profiles of cooperative behaviours differs between students working in heterogeneous groups and those working in homogeneous groups.

\subsubsection{Predictors of individual learning outcomes}

For evaluating the contribution of individual- and group-level perspective-taking ability, cooperative behaviour profiles, and reading comprehension to cooperative learning outcomes, a multilevel analysis was used to take into account the hierarchical data structure (i.e., students working in groups) when predicting students' individual learning outcomes. The dependent variable was the learning outcome measure (i.e., individual score on the knowledge test), and the independent variables at the individual level were students' profile membership (dummy-coded), cognitive perspective taking, social perspective taking, and reading comprehension (dummy-coded with the largest class serving as the baseline category as suggested by Field, 2009). The correlations between all individual-level variables can be found in Table 3. Group-level perspective-taking ability (e.g., heterogeneous and homogeneous composition) was added as a group-level predictor.

Table 2

Descriptive statistics

\begin{tabular}{lcccc}
\hline \multicolumn{1}{c}{ Variable } & \multicolumn{1}{c}{$M$} & \multicolumn{1}{c}{$S D$} & Min. & Max. \\
\hline Individual learning outcomes & 7.46 & 2.14 & 2.00 & 11.00 \\
Cognitive perspective taking & & & & \\
IRI Fantasy & 3.34 & 0.86 & 1.29 & 5.00 \\
IRI Perspective taking & 3.21 & 1.71 & 4.86 & 4.86 \\
RME & 18.87 & 2.96 & 11.00 & 25.00 \\
Social perspective taking & & & & \\
IRI Empathic concern & 3.36 & 0.72 & 1.50 & 5.00 \\
EAQ Differentiating emotions & 2.42 & 0.41 & 1.14 & 3.00 \\
EAQ Verbal sharing & 2.16 & 0.60 & 1.00 & 3.00 \\
EAQ Not hiding & 1.99 & 0.54 & 1.00 & 3.00 \\
EAQ Bodily awareness & 1.95 & 0.50 & 1.00 & 3.00 \\
EAQ Other's emotions & 2.50 & 0.46 & 1.00 & 3.00 \\
EAQ Analyses of emotions & 2.13 & 0.48 & 1.00 & 3.00 \\
CITO reading comprehension & $\%$ & & & \\
Level A & 32.5 & & & \\
Level B & 24.2 & & & \\
Level C & 20.8 & & & \\
Level D+E & 21.6 & & & \\
\hline
\end{tabular}

Note. IRI $=$ Interpersonal Reactivity Index. $\mathrm{RME}=$ Read the Mind in the Eyes-test. EAQ $=$ Emotion Awareness Questionnaire. 
Table 3

Correlations between individual-level variables

\begin{tabular}{llccccc}
\hline \multicolumn{1}{c}{ Variable } & 1 & 2 & 3 & 4 & 5 \\
\hline 1 & Individual learning outcomes & - & & & & \\
2 & Cognitive perspective taking & .09 & - & & & \\
3 & Social perspective taking & .07 & $.40^{*}$ & - & & \\
4 & Reading comprehension & $-.44^{*}$ & -.25 & -.08 & - & \\
5 & Cooperative behaviour & .05 & .07 & .03 & .03 & - \\
$\quad$ profiles & & & & & \\
Note: $*$ p $p<.001$. & & & &
\end{tabular}

\section{Results}

\subsection{Profiles of cooperative behaviours}

Based on the fit indices BIC, AIC3, and CAIC (Hooper, Coughlan, \& Mullen, 2008), we have scrutinized the solutions with two to four profiles (see Table 4). Of these, the four-class solution is chosen based on conceptual appeal as one of the profiles in the three-class solution could be further divided into two meaningful subgroups that differed in terms of the occurrence of off-topic behaviours. Hence, the addition of a fourth class increased the conceptual interpretation of our data as this allowed us to discern profiles based on the prevalence of less effective behaviours. The class-specific profiles of mean frequencies in which each type of behaviour occurred (i.e., the estimated averages of absolute frequencies) are plotted in Figure 1.

Table 4

Model fit indices Latent Profile Analyses

\begin{tabular}{cccccccc}
\hline $\begin{array}{c}\text { Number of } \\
\text { profiles }\end{array}$ & $\begin{array}{c}\text { Log } \\
\text { Likelihood }\end{array}$ & BIC & AIC3 & CAIC & Npar & $\begin{array}{c}\text { Classification } \\
\text { error }\end{array}$ & $\begin{array}{c}\mathrm{R}^{2} \\
\text { entropy }\end{array}$ \\
\hline 1 & -3733.1 & 7665.4 & 7592.1 & 7707.4 & 42 & .000 & 1.000 \\
2 & -3590.2 & 7474.7 & 7366.5 & $\mathbf{7 5 3 6 . 7}$ & 62 & .026 & .901 \\
3 & -3541.5 & $\mathbf{7 4 7 2 . 0}$ & 7328.9 & 7554.0 & 82 & .026 & .924 \\
4 & -3499.5 & 7483.0 & $\mathbf{7 3 0 5 . 0}$ & 7585.0 & 102 & .042 & .910 \\
5 & -3471.3 & 7521.4 & 7308.5 & 7643.4 & 122 & .036 & .924 \\
6 & -3448.9 & 7571.5 & 7323.7 & 7713.5 & 142 & .045 & .926 \\
7 & -3426.8 & 7622.3 & 7339.6 & 7784.3 & 162 & .042 & .934 \\
\hline
\end{tabular}

Note. The lowest fit-indices are set in boldface. BIC $=$ Bayesian Information Criterion. AIC3 = Akaike Information Criterion 3. CAIC $=$ Consistent Akaike Information Criterion. $\mathrm{Npar}=$ number of parameters.

Around $36 \%$ of the students displayed a behaviour pattern that we labelled the captains profile. These captains contributed most by asking questions, giving answers, monitoring the process, and engaging in task-related behaviours and, thus, steered the cooperative learning process substantially. However, the captains also frequently engaged in behaviours less beneficial for learning: They were easily distracted, as illustrated by the high occurrence of off-topic behaviours.

The behaviour patterns of $22 \%$ of students are clustered in a second profile; the hard workers. This profile highly resembles the captains profile, as the hard workers also took the lead in the cooperative process. An important difference between the hard workers and the captains is that the behaviours of students with a hard-worker profile substantially contributed to the group's shared 
knowledge base: They most often brought in new information that was used as an input for the brochure and gave most explanations. In addition, hard workers least often engaged in off-topic behaviours and, instead, kept the focus on the task by engaging in planning and task-related activities.

Almost $30 \%$ of the students engaged in cooperative behaviour patterns clustered in the switchers profile. When retrospectively examining the transcripts of the students with a switcher profile, it is apparent that they constantly switched between on- and off-topic behaviours. In comparison to students in other profiles, the switchers most often engaged in disruptive behaviours. Students in this profile also gave a relatively substantial number of answers, monitored the groups' processes, and engaged in both planning and task-related activities. However, the frequency with which switchers engaged in these behaviours is lower as compared to the captains and hard workers.

The passive-participants profile captures the cooperative behaviours used by $12 \%$ of the students. These students did take part in the cooperative activity, but only if other group members asked them to do so. For example, they gave short answers and summarized what they had read (i.e., input of new information), but did so least often as compared to students with other profiles. Passive participants did not take the initiative and they only asked a minimal number of (non-)specific questions. In comparison to students in other profiles, passive participants far less often engaged in grounding behaviours such as planning and monitoring. 
Average Captains $(35.88 \%)$

absolute

frequencies

of behaviors
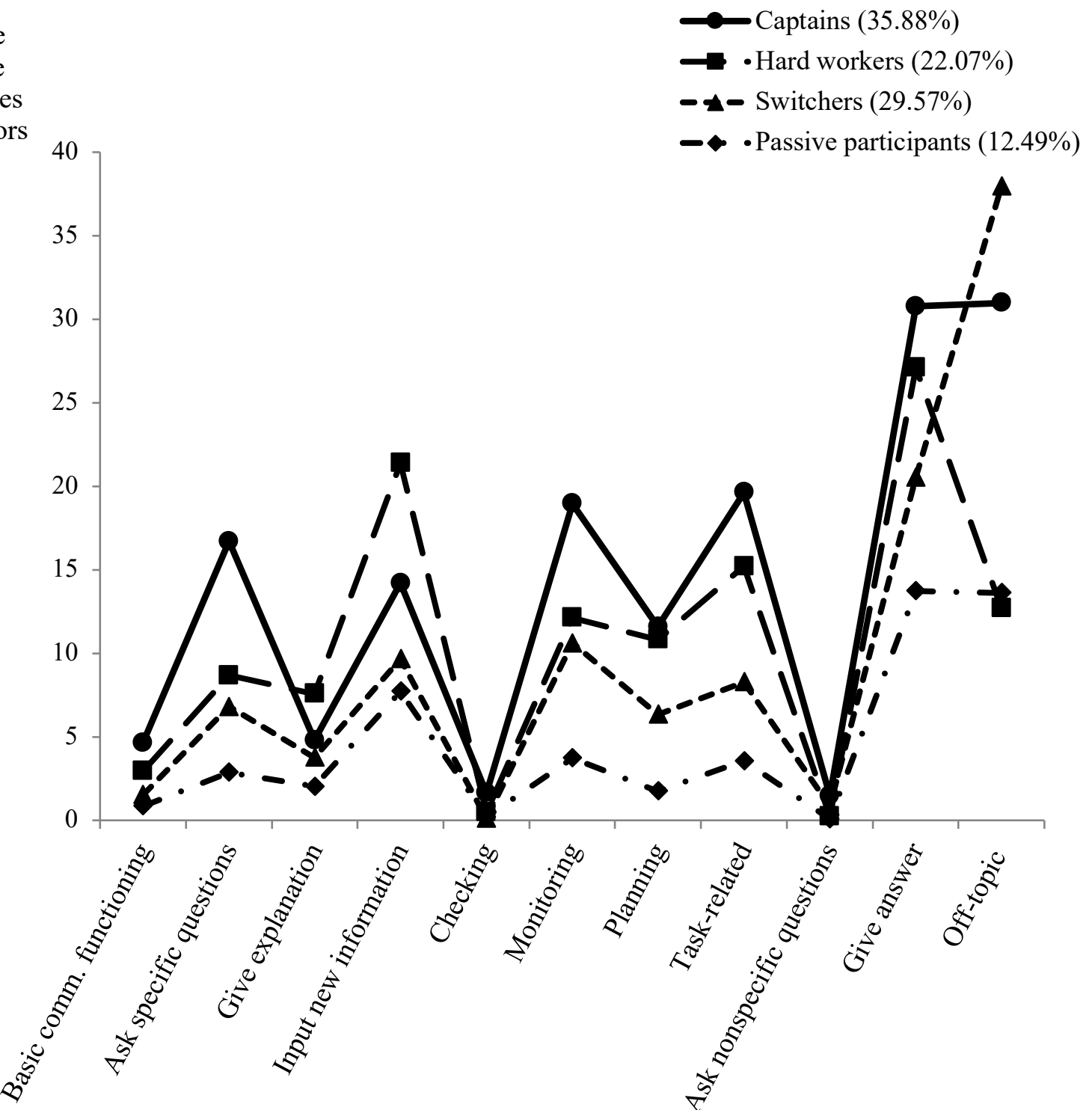

Figure 1. Estimated average absolute frequencies of types of cooperative behaviours for all profiles.

\subsection{Profiles of cooperative behaviours in relation to perspective-taking ability}

Two univariate ANOVAs were used to examine if students' profiles of cooperative behaviours are related to individual-level perspective-taking ability. Specifically, we evaluated if students in the four cooperative behaviour profiles differed in their cognitive and/or social perspective-taking abilities. Table 5 shows that there was no significant relationship between cognitive perspective-taking ability and cooperative behaviour profiles, $F(3,111)=1.94, p=.13$, nor between social perspective-taking ability and cooperative behaviour profiles, $F(3,111)=0.15, p=.93$. Thus, there is no evidence that students in the four profiles differ in their cognitive and/or social perspective-taking abilities. 
Table 5

Univariate ANOVAs

\begin{tabular}{lcccccccccc}
\hline & \multicolumn{1}{c}{$\begin{array}{c}\text { Captains } \\
(n=41)\end{array}$} & \multicolumn{2}{c}{$\begin{array}{c}\text { Hard workers } \\
(n=25)\end{array}$} & \multicolumn{2}{c}{$\begin{array}{c}\text { Switchers } \\
(n=35)\end{array}$} & \multicolumn{2}{c}{$\begin{array}{c}\text { Passive } \\
\text { participants } \\
(n=14)\end{array}$} & & \\
\cline { 2 - 8 } & $M$ & $S D$ & $M$ & $S D$ & $M$ & $S D$ & $M$ & $S D$ & $F$-value & $p$-value \\
\hline $\begin{array}{l}\text { Variable } \\
\text { Cognitive }\end{array}$ & -0.11 & 0.61 & 0.24 & 0.74 & 0.09 & 0.68 & -0.17 & 0.67 & 1.94 & .128 \\
$\begin{array}{l}\text { perspective } \\
\text { taking }\end{array}$ & & & & & & & & & & \\
$\begin{array}{l}\text { Social } \\
\text { perspective } \\
\text { taking }\end{array}$ & 0.01 & 0.42 & 0.00 & 0.50 & -0.03 & 0.46 & 0.06 & 0.05 & 0.15 & .931 \\
\hline
\end{tabular}

Homogeneous groups

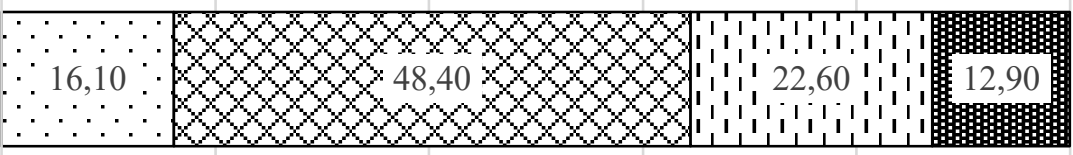

Heterogeneous groups

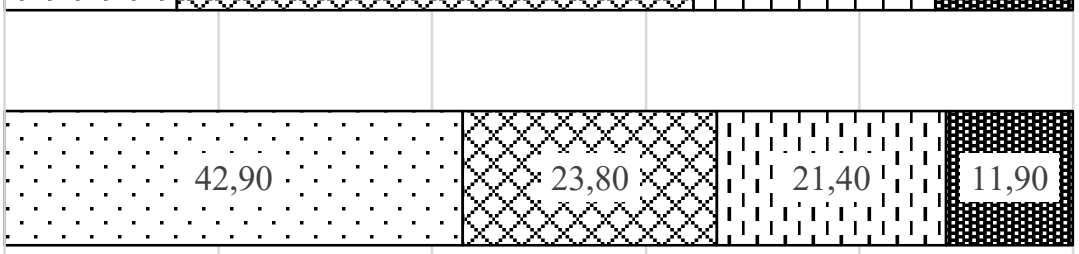

$\begin{array}{lllll}0 \% & 20 \% & 40 \% & 60 \% & 80 \%\end{array}$

$\square$ Captains $\square$ Hard workers $\square$ Switchers 㽗 Passive participants

Figure 2. Profile prevalence (in \%) as a function of group composition.

For answering the second research question, whether students in heterogeneous and homogeneous groups (i.e., group-level perspective-taking ability) engaged in different profiles of cooperative behaviours, a Chi-square test was used. As can be seen in Figure 2, the cooperative behaviour profiles of students in heterogeneous groups indeed differed from those of students in homogeneous groups, $\chi^{2}(3)=9.06, p=.03$. In specific, $48.4 \%$ of the cooperative behaviour patterns of students working in homogeneous groups were classified as a hard-worker profile, whereas this cooperative behaviour profile could only characterize $23.8 \%$ of the behavioural patterns of students in heterogeneous groups. In addition, $42.9 \%$ of the cooperative behaviour profiles of students working in heterogeneous groups were classified as a captain profile, whereas this classification only applied to $16.1 \%$ of the profiles of students working in homogeneous groups. Students in homogeneous and students in heterogeneous groups do not differ with regard to the prevalence of switcher and passiveparticipant profiles.

\subsection{Predictors of individual learning outcomes}

We initially performed a multilevel analysis to examine the relation between types of individuallevel perspective-taking abilities, group-level perspective taking, reading comprehension, profile membership, and individual learning outcomes. However, the intra-class correlation coefficient of $6 \%$ indicated that the variance in students' learning outcomes residing at the group level was too low to warrant a multilevel analysis. In other words, we found no significant differences between the test scores 
of students working in heterogeneous groups and those in homogeneous groups and, thus, there is no evidence for a relation between group-level perspective-taking ability (i.e., group composition) and students' individual learning outcomes. Therefore, multiple regression analysis with stepwise deletion was used to evaluate the prediction of individual learning outcomes by cooperative behaviour profiles, cognitive and social perspective taking, and reading comprehension. All variables were entered simultaneously in the baseline regression model, $F(16,98)=3.94, p<.001, R^{2}=0.39$. The resulting regression coefficients are presented in Table 6 . Next, all non-significant predictors were eliminated using stepwise deletion to facilitate interpretation of effects. The final model was significant, $F(4,113)$ $=8.78, \mathrm{p}<.001$, and explained $23.7 \%$ of the variation in individual learning outcomes.

As Table 7 shows, social perspective-taking ability had a significant positive effect on students' learning outcomes $(B=0.95, p=.018)$. This implies that, on average, higher social perspective-taking ability is reflected in higher test scores. Finally, all levels of the test measuring reading comprehension significantly predicted individual learning outcomes. In comparison to the $25 \%$ of students with the highest level of reading comprehension (A-score), all other students scored significantly lower on the test (with $B$ 's ranging between -1.59 and -2.28 ). We found no evidence for a relation between cooperative behaviour profiles and individual learning outcomes.

Table 6

Regression coefficients of the baseline regression model predicting individual learning outcomes

\begin{tabular}{lccc}
\hline \multicolumn{1}{c}{ Variable } & $B$ & $p$-value & $95 \%$ CI \\
\hline Constant & 8.73 & .000 & {$[7.95,9.51]$} \\
Cognitive perspective taking & -0.27 & .405 & {$[-0.91,0.37]$} \\
Social perspective taking & 1.06 & .018 & {$[0.19,1.94]$} \\
Hard workers* & 0.63 & .207 & {$[-0.35,1.62]$} \\
Switchers* & -0.15 & .737 & {$[-1.04,0.74]$} \\
Passive participants* & -0.15 & .803 & {$[-1.32,1.03]$} \\
CITO reading comprehension - B & -1.69 & .001 & {$[-2.70,-0.69]$} \\
CITO reading comprehension - C & -1.99 & .000 & {$[-2.99,-1.00]$} \\
CITO reading comprehension - D+E & -2.63 & .000 & {$[-3.68,-1.58]$} \\
\hline
\end{tabular}

Note. $n=115 . \mathrm{CI}=$ confidence interval. ${ }^{*}$ The captains profile (dummy-coded) served as the baseline category. ${ }^{\#}$ CITO reading comprehension level A served as the baseline category.

Table 7

Regression coefficients of significant predictors of individual learning outcomes

\begin{tabular}{lccc}
\hline \multicolumn{1}{c}{ Variable } & $B$ & $p$-value & $95 \%$ CI \\
\hline Constant & 8.76 & .000 & {$[8.15,9.36]$} \\
Social perspective taking & 0.95 & .018 & {$[0.15,1.73]$} \\
CITO reading comprehension - B & -1.59 & .001 & {$[-2.52,-0.67]$} \\
CITO reading comprehension - C & -2.04 & .000 & {$[-3.01,-1.07]$} \\
CITO reading comprehension - D+E & -2.28 & .000 & {$[-3.24,-1.33]$} \\
\hline
\end{tabular}

Note. $n=115 . \mathrm{CI}=$ confidence interval. ${ }^{\#} \mathrm{CITO}$ reading comprehension level A served as the baseline category. 


\section{Discussion}

The general aim of the present study was to provide a systematic understanding of how perspective-taking ability contributes to primary-school students' cooperative behaviours and learning outcomes. The present study adds to existing knowledge as we differentiate between types of perspective-taking abilities while taking into account the contribution of both individual-level and group-level perspective-taking ability (i.e., heterogeneous and homogeneous perspective-taking ability groups) to cooperative behaviour profiles and individual learning outcomes of primary-school children. Below, we will first briefly reflect on the nature and meaning of the discerned profiles of cooperative behaviours. Then, we will answer each of our research questions and discuss theoretical and practical implications, limitations, and directions for future research.

\subsection{Profiles of cooperative behaviours}

Because we wanted to learn if - and how — differences in perspective-taking ability are reflected in the range of cooperative behaviours in which primary-school students engage during a whole episode of group work, we first examined to what extent individual differences in primary-school students' cooperative behaviours can be captured in a number of distinct profiles. The results of the LPA show that four profiles of cooperative behaviours can be discerned from the current sample's behavioural data: captains, hard workers, switchers, and passive participants.

The captain and hard-worker profiles approximate the effective leadership role described by Driskell, Driskell, Burke, and Salas (2017), even though the cooperative behaviour profile of the captains entailed a high occurrence of off-topic behaviours. The hard workers contribute to the quality of group work as they gave most explanations as compared to students whose cooperative behaviours could best be captured in one of the other profiles. This finding only partially confirms our hypothesis that a cooperative behavioural profile with a dominance of high-quality helping behaviours can be discerned. Even though we found a difference between the hard workers and all other profiles of cooperative behaviours with regard to the absolute frequencies in which students gave explanations, even the hard workers gave relatively few explanations during group work as compared to all other cooperative behaviours in which they engaged. In addition, we found that the hard workers most often brought in new information serving the group's construction of knowledge (Erkens \& Janssen, 2008). With regard to the switchers, it is interesting to observe that almost a third of the students working in groups continuously (and seemingly effortlessly) switched between behaviours that can be placed on the opposite ends of a 'continuum of effective cooperative behaviours', and thus, are able to correct themselves (or are corrected by their group members) and regain focus as they easily switch back onto task-related behaviours and continue working on the task at hand. The cooperative behaviour profile of the passive participants seems to fit existing notions on social loafing and freeriding, which is a common problem in cooperative learning in which certain group members do not participate or contribute to group work (Kreijns, Kirschner, \& Jochems, 2003). However, our findings indicate that these 'passive participants' do not completely refrain from the task, but instead, engage minimally.

The four profiles were discerned based on the frequency with which each of the cooperative behaviours co-occurred during group work. All students engaged in the whole range of cooperative behaviours, but they differed systematically in the frequency with which each of these behaviours occurred. For example, irrespective of profile membership, students engaged in monitoring activities, but students in the captain profile monitored the group's process most often in comparison to students in other cooperative behaviour profiles.

When we reflect on the nature of the cooperative behaviour profiles as discerned by the LPA, it seems that the profiles provide empirical evidence of the actual occurrence of some of the team-role clusters identified by Driskell and colleagues (2017). Moreover, the discerned profiles align with the functional team roles that are frequently used in cooperative classrooms. Assigning functional roles (i.e., task interdependence) such as manager, planner, or questioner, is an often implemented and effective 
method to structure cooperative learning as it increases group efficiency and task-related interaction (e.g., Strijbos, Martens, Jochems, \& Broers, 2007). Interestingly, the results of the current study suggest that even if a teacher does not actively impose functional roles, these roles occur naturally during group work as students engaged in more or less role-specific behaviours, possibly as a product of the interplay between different team members. When interpreting all results, we stress that the cooperation with other group members, in the end, determines what is said and which cooperative behaviours are needed, and thus, could steer the distribution of team roles (Driskell et al., 2017). Future research could usefully explore if students engage in similar patterns of behaviours while working on tasks differing in complexity or when collaborating with different group members.

\subsection{Profiles of cooperative behaviours in relation to perspective-taking ability}

With regard to our first research question, 'are profiles of cooperative behaviours related to students' individual cognitive and social perspective-taking abilities?', the results of the ANOVAs provide no evidence for a relation between profile membership and individual-level cognitive or social perspective-taking abilities. The absence of such a relation contradicts the hypotheses we held prior to performing the LPA and challenges findings as reported in previous studies. For example, based on the work of Falk and Johnson (1977), we expected that students with higher cognitive perspective-taking abilities would take on a profile characterized by higher frequencies of task-oriented behaviours such as checking, planning, monitoring, and input of new information (i.e., grounding behaviours). And following Cigala and colleagues (2015), we expected that the cooperative behaviours of students with higher social perspective-taking abilities could be captured in a profile in which high-quality helping behaviours prevail. However, the results of the LPA show that both students allocated to a captain profile and those allocated to a hard worker profile often engage in different types of effective grounding and helping behaviours, and as a result, we could not make a clear-cut distinction between cognitivelyoriented and social cooperative behaviour profiles behaviours to evaluate our hypotheses.

Another explanation for the fact that that the discerned interactive roles students took on during group work could not uniquely be related to either type of individual perspective-taking ability could stem from the group composition used in the current study: Students who scored high on cognitive perspective-taking measures were placed together with students with higher social perspective-taking abilities in homogeneous groups, and in heterogeneous groups students varying in perspective-taking ability worked together. We hypothesize that this has led to a situation in which the typical behaviours described in previous studies (e.g., stronger engagement with high-quality helping behaviour if you score high on social perspective-taking measures) possibly are counterbalanced by behaviours in which other group members engaged during group work. For example, it could be that in heterogeneous groups, students with higher social perspective-taking skills refrained from high-quality helping behaviours because none of the cooperating partners with lower perspective-taking abilities engaged in these behaviours. We suppose that more pronounced helping-behaviour and grounding profiles could be discerned if we distinguish between homogeneous cognitive perspective-taking ability groups and homogeneous social perspective-taking ability groups.

With regard to our second research question, 'do students in heterogeneous and homogeneous perspective-taking groups engage in different patterns of cooperative behaviours?', the empirical evidence suggests that perspective taking conceptualized at the group level and profile membership are related. The cooperative behaviours of students in homogeneous groups (i.e., all group members with strong perspective-taking abilities) were most often classified as a hard-workers profile, whereas the prevalence of the captain profile is higher among students in heterogeneous groups. This is noteworthy because the general assumption is that forming heterogeneous groups augments learning gains as cooperating partners are then stimulated to bring in a variety of skills and knowledge facilitating group discussion (e.g., Baer, 2003). However, this assumption stems from research focusing mostly on cognitive ability levels such as mathematical performance or language proficiency (e.g., Baer, 2003; Cohen, 1994; Mouw, Saab, Janssen, \& Vedder, 2019). When group composition is based on group 
members' social skills such as perspective-taking ability, different processes may come into play. However, a word of caution is advised as a Chi-square distribution does not take into account the hierarchical nature of the data. Instead, we have disaggregated group-level data to the individual level, leading to an exaggeration of the sample size for the grouping variable which increases the chance of a Type 1 error (Janssen et al., 2013). Future research on the relation between group-level characteristics and profiles of cooperative behaviours should, therefore, include statistical approaches that can deal with nested categorical data.

\subsection{Predictors of individual learning outcomes}

The third research question was, 'how do individual- and group-level perspective-taking ability and cooperative behaviour profiles contribute to individual students' cooperative learning outcomes?' To control for relevant student characteristics, we included levels of reading comprehension in the regression analysis. Lower levels of reading comprehension resulted in lower test scores, which can be explained by the textual nature of the task. With regard to perspective taking, we found that cognitive perspective taking could not predict individual learning outcomes. The absence of a relationship between cognitive perspective taking and individual learning outcomes is remarkable as it contradicts our hypothesis and previous lines of research (Falk \& Johnson, 1977; Johnson, 1971). The lack of predictive power of cognitive perspective taking in the context of cooperative learning could be the result of maturational differences between the perspective-taking abilities of the (young) adults participating in previous studies and the primary-school students participating in the current study (Epley, Morewedge, \& Keysar, 2004; Pons, Harris, \& De Rosnay, 2004). Hawk and colleagues (2013) found that scores on the Perspective Taking and Fantasy scales (i.e., scales from in the Interpersonal Reactivity Index that are indicators of cognitive perspective-taking ability) are lower for early adolescents (13-year-olds) than for late adolescents (18-year-olds). Hence, our findings could point to a developmental difference in children and adults' engagement in effective cooperative behaviours as a function of (types of) perspective-taking ability, and thus, warrants further examination.

Interestingly, our results suggest that social perspective taking does play a role in the context of cooperative learning. More specifically, we found that students with higher social perspective-taking abilities score higher on the individual test tapping into the information that was discussed during group work as compared to peers with lower social perspective-taking abilities. It should be noted that we found no evidence that this result is a function of a (cor)relation between social perspective taking and reading comprehension ability. The results of the current study extend previous studies, such as those of Johnson (1975a, 1975b), who reported on a relationship between fourth-grade students' social perspective-taking abilities and their predisposition to cooperate. Our results suggest that the influence of social perspective-taking ability reaches beyond a mere disposition towards group work and possibly even affects the quality of learning. Being able to engage in other-oriented feelings of empathy and experiencing, understanding, and appropriately responding to emotional aspects evoked by the social context of cooperation in which a group functions as a collective and social entity (Järvenoja \& Järvelä, 2016), possibly supported adequate group functioning. Working together on an assignment not only implies cognitive engagement with (and coordination of) task-related aspects but also requires cooperators to get along with each other for the sake of task completion (e.g., Barron, 2003; Kreijns et al., 2003). However, being confronted with diverging points of view and strong opinions can lead to cognitive conflict, often accompanied by negative emotional associations or arousal (Järvenoja \& Järvelä, 2016) that impede effective cooperative behaviours such as grounding and helping behaviours. The results of the current study may suggest that even in primary-school settings, social perspectivetaking ability could function as a mechanism facilitating groups to overcome these differences on an emotional level. Higher social perspective-taking ability enables group members to recognize, control, or regulate their own and others' situational interpretation of the social context and ensuing emotional states. Adopting such an affective - instead of a cognitive - point of view to cope with these emotional experiences might have helped groups to overcome differences, restore their working climate, motivational well-being, and regain task focus (e.g., Järvenoja \& Järvelä, 2009, 2016). 
The last individual characteristic included in the regression analysis was cooperative behaviour profile membership. Unexpectedly, the inclusion of profile membership did not reach statistical significance. This could stem from the fact that the profiles were based on a mixture of effective (i.e., basic communicative functioning, grounding, and high-quality helping behaviours) and ineffective, yet frequently occurring cooperative behaviours (i.e., off-topic behaviours and low-quality helping behaviours). In a similar vein, some of the behaviours were task-related, whereas others pertain to social aspects of cooperation. One direction for future research is to code episodes of interaction along a social dimension and a task-related dimension, for example, corresponding to the sociability and taskorientation dimensions of Driskell and colleagues (2017). This way, it is possible to examine if perspective-taking ability can predict profile membership if the discerned cooperative behaviour profiles more specifically represent a social or a task-related dimension.

\subsection{Conclusion}

The added value of the present study lies in the fact that discerning profiles of cooperative behaviours more closely reflects what actually takes place during a cooperative learning task. In addition, the four discerned profiles shed light on which behaviours of cooperating primary-school students co-occur in which frequency. Furthermore, we found that students allocated to these four profiles of cooperative behaviours do not differ in their cognitive or social perspective-taking abilities, suggesting there is no relation between individual-level perspective-taking ability and cooperative behaviours such as grounding, helping behaviours, and basic communicative functioning. Moreover, we now understand that grouping students based on a combination of cognitive and social perspectivetaking ability measures does not necessarily have a direct benefit for individual learning outcomes. However, group composition does seem to play a role in the combination of cooperative behaviours in which students engage during group work, and thus, possibly functions as a mechanism facilitating effective interaction processes that are essential for learning. Last, our study is one of the first to show a differential effect of types of perspective taking on individual learning as social, but not cognitive, perspective-taking ability positively predicts learning in a cooperative context. All in all, our findings suggest that the relationship between perspective taking, cooperative behaviours, and individual students' learning outcomes is not as straightforward as previously documented. On the contrary, it seems that this relation is highly susceptible to the level of measurement and the conceptualization of perspective-taking ability. Hence, acknowledging perspective taking as a group-level attribute seems to be a fruitful endeavour when the goal is to understand how grouping students influences individual students' engagement in cooperative behaviours, whereas adopting a multidimensional approach at the individual level by differentiating between cognitive and social perspective-taking ability provides an opportunity to understand the relation between perspective taking and individual students' cooperative learning outcomes.

\section{Keypoints}

- Patterns of cooperative behaviours of 115 fifth-grade students could be captured in four different profiles.

- These profiles are related to perspective taking conceptualized at the group level, but not to individual-level perspective-taking ability.

- Profile membership, cognitive perspective-taking ability, and group-level perspective-taking ability could not predict students' learning outcomes.

- Social perspective-taking ability and reading comprehension did positively predict learning outcomes.

- The effect of perspective-taking ability on cooperative behaviours and learning outcomes depends on its conceptualization and measurement level. 


\section{Acknowledgments}

We thank Irene Enschede, Sharyl van Harlingen, Veerle Hoff, Annelies Keller, Lisanne Noordzij, Mirjam Post, Sanne Samsom, Nicole Spaans, and Inge Vreugdenhil for their help with material construction, data collection, and/or transcription. We also thank all participating fifth-grade students and their teachers who have welcomed us in their classrooms.

\section{References}

Arjava, M., Salovaara, H., Häkkinen, P., \& Järvelä, S. (2007). Combining individual and group-level perspectives for studying collaborative knowledge construction in context. Learning and Instruction, 17, 448-459. doi:10.1016/j.learninstruc.2007.04.003

Asterhan, C. S. C., \& Schwarz, B. B. (2016). Argumentation for learning: Well-trodden paths and unexplored territories. Educational Psychologist, 51, 164-187. doi:10.1080/00461520.2016.1155458

Baer, J. (2003). Grouping and achievement in cooperative learning. College Teaching, 51, 169-175. doi:10.1080/87567550309596434

Baron-Cohen, S., Wheelwright, S., Hill, J., Raste, Y., \& Plumb, I. (2001). The 'Reading the Mind in the Eyes' test revised version: A study with normal adults, and adults with Asperger syndrome or highfunctioning autism. Journal Child Psychopathology Psychiatry, 42, 241-251. doi:10.1111/14697610.00715

Barron, B. (2003). When smart groups fail. The Journal of the Learning Sciences, 12, 307-359. doi:10.1207/S15327809JLS1203_1

Beersma, B., Bechtoldt, M. N., \& Schouten, M. E. (2018). When ignorance is bliss: Exploring perspective taking, negative state affect and performance. Small Group Research, 49, 576-599. doi:10.1177/1046496418775829

Cigala, A., Mori, A., \& Fangareggi, F. (2015). Learning others' point of view: Perspective taking and prosocial behavior in preschoolers. Early Child Development and Care, 185, 1199-1215. doi:10.1080/03004430.2014.987272

Clark, H. H., \& Brennan, S. (1991). Grounding in communication. In L. B. Resnick, J. M. Levine \& S. Teasley (Eds.), Perspectives on socially shared cognition (pp. 127-149). Washington, DC: American Psychological Association.

Cohen, E. G. (1994). Restructuring the classroom: Conditions for productive small groups. Review of Educational Research, 64, 1-35. doi:10.3102/00346543064001001

Collins, L. M., \& Lanza, S. T. (2010). Latent class and latent transition analysis. Hoboken, NJ: Wiley.

Davis, M. H. (1983). Measuring individual differences in empathy: Evidence for a multidimensional approach. Journal of Personality and Social Psychology, 44, 113-126. doi:10.1037/00223514.44.1.113

Davis, M. H., Conklin, L., Smith, A., \& Luce, C. (1996). Effect of perspective taking on the cognitive representation of persons: A merging of self and other. Journal of Personality and Social Psychology, 70, 713-726. doi:10.1037/0022-3514.70.4.713

Di Eugenio, B., Jordan, P. W., Thomason, R. H., \& Moore, J. D. (2000). The agreement process: An empirical investigation of human-human computer mediated collaborative dialogs. International Journal of Human-Computer Studies, 53, 1071-1075. doi:10.1006/ijhc.2000.0428

Driskell, T., Driskell, J. E., Burke, C. S., \& Salas, E. (2017). Team roles: A review and integration. Small Group Research, 48, 482-511. doi:10.1177/1046496417711529

Egberink, I. J. L., Janssen, N. A. M., \& Vermeulen, C. S. M. (2015). COTAN beoordeling 2015 Leerling,- en onderwijsvolgsysteem begrijpend lezen [COTAN review 2015, evaluation of the system for monitoring educational progress: Reading comprehension]. Amsterdam, the Netherlands: Boom Test Uitgevers.

Epley, N., Morewedge, C. K., \& Keysar, B. (2004). Perspective taking in children and adults: Equivalent egocentrism but differential correction. Journal of Experimental Social Psychology, 40, 760-768. doi:10.1016/j.jesp.2004.02.002 
Erkens, G. (2004). The dynamics of coordination in collaboration. In J. van der Linden \& P. Renshaw (Eds.), Shifting perspectives to learning, instruction, and teaching (pp. 191-213). Dordrecht, the Netherlands: Kluwer Academic Publishers.

Erkens, G. (2005). Multiple Episode Protocol Analysis (Version 4.10) [Computer software]. Utrecht: Utrecht University.

Erkens, G., \& Janssen, J. (2008). Automatic coding of dialogue acts in collaboration protocols. International Journal of Computer-Supported Collaborative Learning, 3, 447-470. doi:10.1007/s11412-008-90526

Erkens, G., Jaspers, J., Prangsma, M., \& Kanselaar, G. (2005). Coordination processes in computer supported collaborative writing. Computers in Human Behavior, 21, 463-486. doi:10.1016/j.chb.2004.10.038

Evers, G. (2008). Programma voor berekening Cito LeesIndex voor het Basisonderwijs (P-CLIB, version 3.0) [computer software]. Arnhem, the Netherlands: Cito.

Falk, D. R., \& Johnson, D. W. (1977). The effects of perspective-taking and egocentrism on problem solving in heterogeneous and homogeneous groups. The Journal of Social Psychology, 102, 63-71. doi:10.1080/00224545.1977.9713241

Field, A. (2009). Discovering statistics using SPSS ( $3^{\text {rd }}$ Ed.). Los Angeles, CA: Sage.

Galinsky, A. D., Ku, G., \& Wang, C. S. (2005). Perspective-taking and self-other overlap: Fostering social bonds and facilitating social coordination. Group Processes and Intergroup Relations, 8, 109-124. doi: $10.1177 / 1368430205051060$

Galinsky, A. D., \& Moskowitz, G. B. (2000a). Perspective-taking: Decreasing stereotype expression, stereotype accessibility, and in-group favoritism. Journal of Personality and Social Psychology, 78, 708-724. doi:10.1037/0022-3514.78.4.708

Gillies, R. M. (2014). Developments in cooperative learning: Review of research. Anales de Psicología, 30 , 792-801. doi:10.6018/analesps.30.3.201191

Hawk, S. T., Keijsers, L., Branje, S. J. T., Van der Graaff, J., De Wied, M., \& Meeus, W. (2013). Examining the Interpersonal Reactivity Index (IRI) among early and late adolescents and their mothers. Journal of Personality Assessment, 95, 96-106. doi:10.1080/00223891.2012.696080

Hickendorff, M., Edelsbrunner, P. A., McMullen, J., Schneider, M., \& Trezise, K. (2018). Informative tools for characterizing individual differences in learning: Latent Class, Latent Profile, and Latent Transition Analysis. Learning and Individual Differences, 66, 4-15. doi:10.1016/j.lindif.2017.11.001

Hooper, D., Coughlan, J., \& Mullen, M. R. (2008). Structural Equation Modelling: Guidelines for determining model fit. Electronic Journal of Business Research Methods, 6, 53-60. Retrieved from http://www.ejbrm.com/volume6/issue1/p53

Janssen, J., Cress, U., Erkens, G., \& Kirschner, P. A. (2013). Multilevel analysis for the analysis of collaborative learning. In C. E. Hmelo-Silver, C. A. Chinn, C. K. K. Chan, \& A. M. O’Donnell, The international handbook of collaborative learning (pp. 41-56). New York, NY: Routledge.

Janssen, J., Erkens, G., Kirschner, P. A., \& Kanselaar, G. (2012). Task-related and social regulation during online collaborative learning. Metacognition and Learning, 7, 25-43. doi:10.1007/s11409-010-90615

Järvelä, S., \& Häkkinen, P. (2002). Web-based cases in teaching and learning - the quality of discussions and a stage of perspective taking in asynchronous communication. Interactive Learning Environments, 10, 1-22. doi:10.1076/1lee.10.1.1.3613

Järvenoja, H., \& Järvelä, S. (2009). Emotion control in collaborative learning situations - do students regulate emotions evoked from social challenges? British Journal of Educational Psychology, 79, 463-481. doi:10.1348/000709909X402811

Järvenoja, H., \& Järvelä, S. (2016). Regulating emotions together for motivated collaboration. In M. Baker, J. Andriessen, \& S. Järvelä (Eds.), Affective learning together: Social and emotional dimensions of collaborative learning (pp. 162-182). New York, NY: Routledge.

Johnson, D. W. (1971). The effectiveness of role reversal: The actor or the listener. Psychological Reports, 28, 275-282. doi:10.2466/pr0.1971.28.1.275

Johnson, D. W. (1975a). Affective perspective taking and cooperative predisposition. Developmental Psychology, 11, 869-870.

Johnson, D. W. (1975b). Cooperativeness and social perspective taking. Journal of Personality and Social Psychology, 31, 241-244. doi:10.1037/h0076285 
Johnson, D. W. (2015). Constructive controversy: Theory, research, practice. Cambridge, UK: Cambridge University Press.

Johnson, D. W., \& Johnson, R. T. (2009). An educational psychology success story: Social interdependence theory and cooperative learning. Educational Researcher, 38, 365-379. doi:10.3102/0013189X09339057

King, A. (2002). Structuring peer interaction to promote high-level cognitive processing. Theory into Practice, 41, 33-40. doi:10.1207/s15430421tip4101_6

Kreijns, K., Kirschner, P. A., \& Jochems, W. (2003). Identifying the pitfalls for social interaction in computer-supported collaborative learning environments: A review of the research. Computers in Human Behavior, 19, 335-353. doi:10.1016/S0747-5632(02)00057-2

Michelon, P., \& Zachs, J. M. (2006). Two kinds of visual perspective taking. Perception \& Psychophysics, 68, 327-337. doi:10.3758/BF03193680

Mouw, J. M., Saab, N., Janssen, J., \& Vedder, P. (2019). Quality of group interaction, ethnic group composition, and individual mathematical learning gains. Social Psychology of Education, 22, 383403. doi: 10.1007/s11218-019-09482-w

Mouw, J. M., Saab, N., Pat-El, R. J., \& Van den Broek, P. (2019). Student- and task-related predictors of primary-school students' perceptions of cooperative learning activities. Pedagogische Studiën, 96(2), 98-122.

Oberski, D. (2016). Mixture models: Latent profile and latent class analysis. In J. Robertson \& M. Kaptein (Eds.), Modern statistical methods for HCI (pp. 275-287). Switzerland: Springer International Publishing.

Ortiz, A. E., Johnson, D. W., \& Johnson, R. T. (1996). The effect of positive goal and resource interdependence on individual performance. The Journal of Social Psychology, 136, 243-249. doi:10.1080/00224545.1996.9713998

Pons, F., Harris, P. L., \& De Rosnay, M. (2004). Emotion comprehension between 3 and 11 years: Developmental periods and hierarchical organization. European Journal of Developmental Psychology, 1, 127-152. doi:10.1080/17405620344000022

Pronin, E., Puccio, C. T., \& Ross, L. (2002). Understanding misunderstanding: Social psychological perspectives. In T. Gilovich, D. Griffin, \& D. Kahneman (Eds.), Heuristics and biases: The psychology of intuitive judgment (pp. 636-665). Cambridge, UK: Cambridge University Press.

Rieffe, C., Oosterveld, P., Miers, A. C., Terwocht, M. M., \& Ly, V. (2008). Emotion awareness and internalizing symptoms in children and adolescents: The Emotion Awareness Questionnaire revised. Personality and Individual Differences, 45, 756-761. doi:10.1016/j.paid.2008.08.001

Ruby, P., \& Decety, J. (2004). How would you feel versus how do you think she would feel? A neuroimaging study of perspective-taking with social emotions. Journal of Cognitive Neuroscience, 16, 988-999. doi:10.1162/0898929041502661

Strijbos, J. W., Martens, R. L., Jochems, W. M., \& Broers, N. J. (2007). The effect of functional roles on perceived group efficiency during computer-supported collaborative learning: A matter of triangulation. Computers in Human Behavior, 23, 353-380. doi:10.1016/j.chb.2004.10.016

Tjosvold, D., \& Johnson, D. W. (1977). Effects of controversy on cognitive perspective taking. Journal of Educational Psychology, 69, 679-685. doi:10.1037/0022-0663.69.6.679

Tjosvold, D., \& Johnson, D. W., \& Johnson, R. T. (1984). Influence strategy, perspective-taking, and relationships between high- and low-power individuals in cooperative and competitive contexts. The Journal of Psychology, 116, 187-202. doi:10.1080/00223980.1984.9923636

Trötschel, R., Hüffmeier, H., Loschelder, D. D., Schwartz, K., \& Gollwitzer, P. M. (2011). Perspective taking as a means to overcome motivational barriers in negotiations: When putting oneself into the opponent's shoes helps to walk toward agreements. Journal of Personality and Social Psychology, 101, 771-790. doi:10.1037/a0023801

Vermunt, J. K., \& Magidson, J. (2013). Technical guide for Latent GOLD 5.0: Basic, advanced, and syntax. Belmont, MA: Statistical Innovations Inc.

Vogindroukas, I., Chelas, E. N., \& Petridis, N. E. (2014). Reading the Mind in the Eyes test (children's version): A comparison study between children with typical development, children with highfunctioning autism and typically developed adults. Folia Phoniatrica et Logopaedica, 66, 18-24. doi: $10.1159 / 000363697$ 
Webb, N. M. (2013). Information processing approaches to collaborative learning. In C. E. Hmelo-Silver, C. A. Chinn, C. K. K. Chan, \& A. O’Donnell. (Eds.), The international handbook of collaborative learning (pp. 19-40). New York, NY: Routledge.

Webb, N. M., Farivar, S. H., \& Mastergeorge, A. M. (2002). Productive helping in cooperative groups. Theory into Practice, 41, 13-20. doi:10.1207/s15430421tip4101_3

Wegerif, R., \& Mercer, N. (1996). Computers and reasoning through talk in the classroom. Language and Education, 10, 47-64. doi:10.1080/09500789608666700

Wellman, H. M. (2018). Theory of mind: The state of the art. European Journal of Developmental Psychology, 15, 728-755. doi:10.1080/17405629.2018.1435413

\section{Appendix 1}

Table A1

Cooperative learning rules

\begin{tabular}{|c|c|}
\hline Process & Rules \\
\hline Basic rules & $\begin{array}{l}\text { Pay attention to each other by listening, giving compliments, participating } \\
\text { actively, making eye contact, giving others the opportunity to speak and/or finish } \\
\text { their sentence, and encouraging group members to continue their reasoning. }\end{array}$ \\
\hline $\begin{array}{l}\text { Helping } \\
\text { behaviour }\end{array}$ & $\begin{array}{l}\text { - Ask specific questions when you need help or if something is unclear. } \\
\text { - Always provide help: Give clear answers, but preferably explanations if a peer } \\
\text { asks a question. } \\
\text { - Explain something in a different manner if your explanation is not understood } \\
\text { the first time. }\end{array}$ \\
\hline Grounding & $\begin{array}{l}\text { Check your group members' frame of reference. Do all group members } \\
\text { understand the task? Do all group members understand your explanation? Do all } \\
\text { group members agree with decisions made? } \\
\text { - It is ok to disagree, but always give arguments and explain why you disagree. }\end{array}$ \\
\hline
\end{tabular}

